\title{
Worldwide Shadow Education Epidemic and Its Move toward Shadow Curriculum
}

\author{
Yaghoob Javadi \\ Department of Language Teaching and Translation, Varamin-Pishva Branch, Islamic Azad University, Varamin, Iran \\ Fakhereh Kazemirad \\ Department of Language Teaching and Translation, Varamin-Pishva Branch, Islamic Azad University, Varamin, Iran
}

\begin{abstract}
Shadow education has become a widespread phenomenon worldwide and is now an unavoidable learning space for many students. It challenges the traditional notion of factory-like one-size-fits-all education and provides students with more personalized learning. Moreover, it goes beyond shadowing the formal education and holds a mirror up to the formal education to reveal its shortcomings. Although more studies worldwide are focusing on the phenomenon, its scope, characteristics, history, and functionality remain underexplored. Therefore, shadow education should be considered as an emerging focus of recent curriculum studies and should not be disregarded by researchers who attempt to understand where, how, what, and with whom students learn. The present article elaborates on a new conceptualization of 'shadow education' and one of its components, 'shadow curriculum', which is a new focus of curriculum studies aiming for individual students' academic success in formal education. First, we deal with shadow education and its forms and features, and then move toward the concept and characteristics of shadow curriculum.
\end{abstract}

Index Terms - shadow education, shadow curriculum, private tutoring, curriculum studies

\section{INTRODUCTION}

Traditionally, education has been based on formal schooling and "the school curriculum was the only guideline for determining what and how students learned at school or at home" (Kim \& Jung, 2019a, p. 14). Nevertheless, in the recent decades, academic success can no longer be attributed solely to public education and many students achieve their academic goals by learning in the 'shadow education' which is commonly understood as private education outside of formal public schooling. (Kim \& Jung, 2019a). Therefore, shadow education expanded in response to perceptions that public schooling was inadequate to guarantee academic success (Byun, 2010). This phenomenon can also help us critically question the historically 'sacred' status of public schooling (Kim \& Jung, 2019b).

Students and parents do not have blind faith in public education today (Kim \& Jung, 2019a) and believe that shadow education centers employ more and better educational practices and teachers (Kim \& Kim, 2012, 2015; Paramita, 2015; Yang \& Kim, 2010). In fact, shadow education challenges the authority of schooling and instructors by altering students' attitudes toward public education. Thus, many students value shadow education more than public education (Kim, 2016; Paramita, 2015), believing that shadow education teachers understand and guide them better (Kim \& Kim, 2012, 2015; Mawer, 2015; Paramita, 2015). They supplement their learning through shadow education (Bray, 1999; Kim, 2016; Ozaki, 2015), because it provides various curricula and materials that are mostly related to public schools to enrich schooling (Kim, 2016; Kim \& Jung, 2019a; Ozaki, 2015). In addition, parents are much more active and powerful in the shadow education sector than in public education and actively search for educational opportunities that best meet the needs and goals of their children (Kim \& Jung, 2019a). Unlike public schooling, shadow education enables students and parents to make decisions about courses, curriculum materials and even instructors (Kim \& Jung, 2019a). Therefore, "in an era when shadow education is reshaping student learning and arguably the whole landscape of education in many countries worldwide, shadow education, and more specifically shadow curriculum, should emerge as a new research area in the field of curriculum studies" (Kim \& Jung, 2019a, p. 16).

The present paper tries to discuss the historical development of shadow education and its move toward shadow curriculum. Firstly, it focuses on how shadow education has been defined by different researchers at different times. Then, it provides detailed explanation on different forms of shadow education and also deals with what forms of shadow education emerge in different contexts. Next, the paper looks at the conceptualization of shadow curriculum as a new focus of curriculum studies and explains characteristics of shadow education curricula in order to understand what characteristics attract students and parents. Finally, backwash effects of shadow education on mainstream schooling and the issue of inequalities caused by shadow education are addressed.

\section{RESEARCH DEVELOPMENT}

Historically, shadow education has been most widespread in East Asian countries such as South Korea, Japan, China, Taiwan, and Singapore (Dawson, 2010; Jung, 2018; Kim, 2016; Kim \& Jung, 2019b; Mori \& Baker, 2010), but it has 
expanded significantly worldwide since the start of the twenty-first century (Bray, 2017; Kim, 2016; Kim \& Jung, 2019b; Park, Buchmann, Choi \& Merry, 2016). "Students' participation in shadow education has gained increasing interest from researchers due to its tremendous growth" (Dwita, Cheisviyanny, Helmy, \& Marwan, 2018, p. 551) and researches have been done to find out what impacts and consequences shadow education leaves on students, families, schools, public school systems, and societies (Jung, 2018). On the positive side, studies on shadow education have acknowledged its important contribution to students' academic success, college admission (Buchmann, Condron, \& Roscigno 2010), and also their social development (Gök 2010). On the other hand, researchers have identified undesirable consequences of shadow education that Bray (2011, p. 14) calls "backwash", including negatively impacting students' development (Gillen-O’Neel, Huynh, \& Fuligni 2013; Park et al. 2016; Yamamoto \& Brinton 2010), as well as increasing students workloads, parental financial burdens, existing social inequalities, and excessive competition and anxiety of students and parents (Jung, 2018; Kim, 2016). "Existing research has revealed enough of shadow education's pervasiveness, seriousness, and negative effects to alarm educators and researchers, and to ensure that shadow education shall not be ignored" (Jung, 2018, p. 272). Although, shadow education has been the focus of much attention in the fields of comparative education, education and policy, sociology of education, education and economics, and lifelong education (Jung, 2018), it has not received attention from curriculum theorists (Kim \& Jung, 2019b). Empirical research has indicated that in many contexts shadow education is a great force that is shaping our education sector and academic success is seriously influenced by participation in shadow education (Nam \& Chan, 2019). Thus, Curriculum research cannot be restricted to schools and research needs to be conducted to uncover shadow education impacts in depth (Nam \& Chan, 2019).

\section{DeFINING Shadow EduCATION AND ITs SubCATEGORIES}

De Silva, Gunawardena, Jayaweera, Perera, Rupasinghe, and Wijetunge (1991) introduced the idea of shadow education to academia using the term 'private supplementary tutoring' when referring to this kind of education (Kim \& Jung, 2019b). After that, Stevenson and Baker (1992) defined shadow education as "a set of educational activities that occur outside formal schooling and are designed to enhance the student's formal school career" (p. 1639). Later, Baker, Akiba, LeTendre, and Wiseman (2001) defined shadow education as "outside-school learning activities paralleling features of formal schooling used by students to increase their own educational opportunities" (p. 2). Buchmann, Condron, and Roscigno (2010) also defined shadow education as "educational activities, such as tutoring and extra classes, occurring outside of formal schooling designed to improve a student's chance of successfully moving through high school graduation and into a college of their choice" (p. 436).

"The metaphor of 'shadow' first emerged in discourse about shadow education in Malaysia, Singapore, and Japan" (Kim \& Jung, 2019b, p. 26), and helped researchers and readers understand the overall implications of the phenomenon (Bray, 2013). Bray (1999) popularized the term 'shadow education', emphasizing the mimicry character of shadow education, while framing mainstream schooling as the source of light. He claimed that the metaphor of the shadow is suitable for several reasons:

First, private supplementary tutoring only exists because the mainstream education exists; second, as the size and shape of the mainstream system change, so do the size and shape of supplementary tutoring; third, in almost all societies much more public attention focuses on the mainstream than on its shadow; and fourth, the features of the shadow system are much less distinct than those of the mainstream system. (Bray, 1999, p. 17)

Malik (2017) considered various definitions of shadow education and argued that these can result in confusion and ambiguity, particularly about the issue of supplementation and privateness, which Bray (2007 [1999]) considered important parameters of shadow education. He defined shadow education as "activities that are meant to help the students to improve their school learning in examinable subjects" (2017, p. 20). He also explained that "these activities must be paid by the students or on their behalf, and provided privately outside of formal school responsibilities" (2017, p. 20). Further, he divided shadow education into three subcategories according to their characteristics and impacts; including 'shadow teaching', 'shadow curriculum', and 'prerecorded academic aids'. Shadow teaching which is the first subcategory of shadow education refers to any kind of supplementary teaching provided by tutors, teachers, or any other person with or without physical presence such as online teaching (Malik, 2017). It is real time teaching; therefore, prerecorded lectures are not part of this category in that their impact, how they are delivered and received are totally different from face-to-face or live lectures (Malik, 2017). Like shadow education, shadow teaching is considered as profit making and free supplementary teaching is not part of it (Malik, 2017). The second subcategory of shadow education is shadow curriculum which includes all textual help books, eBooks, guides, helping materials, notes, solved and unsolved materials (Malik, 2017). These materials need to be bought or hired and any materials obtained or used free of cost would not be a part of this category (Malik, 2017). The third subcategory of shadow education introduced by Malik (2017) is prerecorded academic aids which include all the lectures, lessons, explanations or solutions that are delivered in the form of prerecorded online lectures, CDs, audio messages or videos.

\section{FORMS OF SHADOW EDUCATION}


Kim, Gough, and Jung (2018) identified five main forms of shadow education based on Bray's (2011) categorization of shadow education that include one-to-one, pairs, small groups, and classroom-based instruction. It is believed that this categorization of shadow education is based chiefly on student-teacher ratio (Kim et al., 2018; Kim \& Jung, 2019a). The five forms of shadow education which allow students and parents to make choices about learning space, time, methods, and even teachers include: (1) home-visit private tutoring, (2) private tutoring institutes, (3) subscribed learning programs, (4) Internet-based private tutoring, and (5) after-school programs (Kim et al., 2018; Kim \& Jung, 2019b).

\section{A. Home-visit Private Tutoring}

Home-visit private tutoring (HVPT) is the most individualized form of shadow education (Kim et al., 2018) that provides students with a face-to-face customized tutoring, usually at their home (Kim \& Jung, 2019b). This is considered as the most traditional form of shadow education in which tutors usually work one-on-one with a student, but sometimes work in small groups (Kim \& Jung, 2019b). Unlike schools, which are often restricted to governmentdesignated timetables, textbooks, and curricula, HVPT is flexible in terms of instructional materials, methods, and time and location and this flexibility may be the most distinctive feature of HVPT (Kim \& Jung, 2019b). In fact, HVPT is unsystematic and fluid and tutors are not restricted to a structured curriculum in order to allow immediate modification of curricula based on the individual learner's needs (Kim \& Jung, 2019b). Additionally, HVPT involves an intimate relationship between a tutor and tutee(s). This means that tutors not only help students with their academic needs, but also meet their emotional, affective, and mental needs in a close relationship (Kim \& Jung, 2019b). Research shows that students who engage in HVPT experience more open and honest communication with tutors than to school teachers (Kim, 2016; Kim \& Jung, 2019b; Yang \& Kim, 2010). Since there are no formal requirements for HVPT, private tutors can range from high school or university students with no pedagogical training to specialized and experienced tutors and even to mainstream teachers (Kim \& Jung, 2019b). HVPT is used mostly by students from relatively wealthy families, because fees are higher than any other form of shadow education (Kim, 2016; Kim et al., 2018; Kim \& Jung, 2019a). However, in some countries, like the United States and Japan, governments fund tutoring for poor and underachieving students (Kim \& Jung, 2019a; Mawer, 2015).

\section{B. Private Tutoring Institutes}

Private tutoring institutes (PTIs) are the most school like form of shadow education because they have their own physical spaces with classrooms and buildings (Kim \& Jung, 2019a). They included differentiated classes and group students based on academic levels, abilities, and needs (Kim \& Jung, 2019b). Typically, students attend private tutoring classes three times a week during the school year and every day during the vacations (Kim, 2016). Class sizes are usually smaller than school classes and may range from 7 to 15 students or more (Kim et al., 2018; Kim \& Jung, 2019a). PTIs have their own formulaic curriculum and instruction, formalized timetables, materials, classes, and assessment or evaluation methods (Bray, 2011; Kim, 2016; Kim et al., 2018). Unlike schools which use formal exams once or twice a semester or year, PTIs usually use ongoing assessments and diagnostic tools to check student understanding of course content and assess each student's study progress, academic strengths and weaknesses, and overall attitude about school and learning (Kim \& Jung, 2019b). PTIs provide educational counseling services that positively contributes to students' academic, social, and psychological development and enhances their general welfare (Kim \& Kim, 2012, 2015, Kim \& Jung ,2019b). Kim and Jung (2019b) believe that PTI has become a big industry in many countries in that many PTIs have recently become franchised and expanded rapidly throughout the world. According to Kim and Jung (2019b), PTIs can be classified into four main types: One subject PTIs, Comprehensive PTIs, PTIs for talented students, and Test preparation specialized PTIs. 'One subject PTIs' focus on one particular subject such as language, mathematics, or science; for example, English language PTIs which are common in East Asia (Kim \& Jung, 2019b). 'Comprehensive PTIs' focus on all school subjects to provide students with remedial and enhancement lessons, provide assistance with school assignments and regular counseling, help students build fundamental learning skills, help maintain or improve their GPA, and prepare students for high-stake tests (Kim \& Jung, 2019b). 'PTIs for talented students' target advanced and high-achieving students and provide them with accelerated learning opportunities, which public schools cannot or do not (Kim \& Jung, 2019b). 'Test preparation specialized PTIs' provide admission-oriented teaching and preparation for various exams. In fact, for successful exam preparation, students are provided with strategies, learning methods, types of questions, and admission counseling and information (Bray, 2013).

\section{Subscribed Learning Program}

A subscribed learning program (SLP) is defined by Kim and Jung (2019a) as "a highly standardized and systematic tutoring program provided by large, franchised enterprises such as Kumon, Red Pen, Prunet, and Nunnoppi” (P. 4). These enterprises develop their materials using their own curricular and instructional strategies that is only available by subscription and are delivered via mail, email and online (Kim et al., 2018). In fact, SLPs have systematized curricula, constituting of subdivided levels to provide students with daily and weekly materials and worksheets (Kim \& Jung, 2019b). In SLP, students master the content and fundamental skills through repetitive drills and feedback (Kim \& Jung, $2019 \mathrm{~b}$ ) and also have the chance to follow the instructional materials step-by-step and at their own pace at home (Kim, et al., 2018). In addition, SLPs homework management helps students develop good learning habits (Kim \& Jung, 
2019b). Although most SLP companies send tutors to students' home like HVPT, the role of tutors in this type of shadow education is different in that they evaluate student progress and degree of understanding (Kim et al., 2018; Kim \& Jung, 2019a), analyze their work, identify weak points, and provide additional explanation until students fully understand the material and can move on to more advanced topics (Kim \& Jung, 2019b). According to Kim and Jung (2019b), SLP is delivered in two main ways: 'home-visit subscribed learning programs' which are the most common and traditional form of SLP and focus on distributing printed worksheets to students and an instructor visit regularly; and 'online/ telephone subscribed learning programs' which are technology-based and focus on online and telephone services to manage learning without visiting students at home. "Students are often motivated to learn by participating in online educational platforms that gives virtual points and rewards to students when they complete online lectures, games, math problems, and reading materials" (Kim \& Jung, 2019b, P. 74).

\section{Internet-based Private Tutoring}

"Internet-based private tutoring (IPT) combines the advantages of private tutoring and highly developed technologies" (Kim \& Jung, 2019b, P. 74) and helps students and tutoring institutions overcome geographical and temporal barriers (Kim et al., 2018; Kim \& Jung, 2019b). IPT allows students to access to high quality lessons and lectures from famous instructors across their country or even other developed countries (Kim \& Jung, 2019b). It has also improved matching between students and instructors and has reduced inequalities in information acquisition through distant education (Bukowski, 2017). IPT allows students to utilize their time efficiently and requires them to be more self-managed independent learners (Kim \& Jung, 2019b). Additionally, IPT companies develop their own online content, curriculum, teaching, and learning materials and make numerous lectures, programs, information, and services available online (Kim \& Jung, 2019b). These companies are growing exponentially due to their ubiquity and relatively low tuition cost and as a result many traditional offline shadow education companies have now expanded their models to include the Internet (Kim \& Jung, 2019b). Kim and Jung (2019b) introduced three main types of IPTs: 1) Archived online lecture refers to educational video files that are viewable on a designated Web site and students can access them on the Web sites anytime, anywhere, via their computer, PMP, tablet, or smartphone (Kim \& Jung, 2019b). Students can watch the files repeatedly for a designated time period after paying for them (Kim \& Jung, 2019b). 2) Live online tutoring allows real-time student-teacher interaction in which learner/ learners simultaneously log into the system and receive lectures from a tutor (Kim \& Jung, 2019b). 3) Blended learning combines online and offline learning and provides students with prerecorded lectures posted on Web sites (Kim \& Jung, 2019b). "Students can get help from archived online lectures when they cannot understand the content is covered in offline tutoring or lectures, or when they miss a specific lecture" (Kim \& Jung, 2019b, P. 77).

\section{E. Academic After-school Programs}

After-school programs (ASPs) can be defined as "a set of student-centered learning and development activities which are school-based operations but are not a part of the regular curriculum" (Bae \& Jeon, 2013, p. 55). Although other forms of shadow education mainly focus on academic purposes, ASP focuses on diverse purposes and functionalities from school subjects, sports, and arts (Devaney, Smith, \& Wong, 2012; Durlak, Evans \& Leung, 2012; Kim \& Jung, 2019b). Actually, ASPs provide child care and supervised learning in educational environments to students whose parents cannot take care of them after school hours (Kim \& Jung, 2019b). The cost of ASP is often funded or supplemented by governments or nonprofit organizations to fulfill the needs of working parents (Kim \& Jung, 2019b). It is relatively low compared to PTI or HVPT in that they use school classrooms and facilities (Kim \& Jung, 2019b). ASPs usually include government regulation and "originate from a government's desire to reduce academic gaps among students, provide child care, and enhance the results of national academic assessments" (Kim \& Jung, 2019b, p. 82). As Kim \& Jung (2019b) noted, the different practices of ASPs in different countries can be categorized into two main types: 'Subject knowledge-based ASPs' include school subjects and provide students with remedial help, academic help, and test preparation at a low cost (Kim \& Jung, 2019b). Typically, teachers in public education are also teachers in ASPs and receive additional payment for tutoring students who are already their students in the mainstream schooling (Bray, 1999). 'Skill and aptitude ASPs' normally focus on the development of artistic and practical skills and offer various programs, such as sports, cultural arts, performing arts, computer literacy, and life skills (Kim \& Jung, 2019b) which can improve students' attitude, self-confidence, and social skills (Evans \& Leung, 2012).

\section{CONCEPT OF Shadow CuRRICUlum}

Shadow curriculum is one component of the worldwide phenomenon of shadow education (Kim \& Jung, 2019b). It is a new concept of curriculum that focuses attention to student learning outside formal schooling (Kim \& Jung, 2019b). Kim and Jung (2019a) defined shadow curriculum by drawing on existing terminologies, definitions and characteristics of shadow education as "supplementary curriculum out of schooling provided by educational business industries that are aimed for individual students' academic success in formal education" (p. 10). Their definition of shadow curriculum incorporates three main components. First, shadow curriculum focuses on the individual (Kim \& Kim, 2012, 2015; Mawer, 2015; Ozaki, 2015) and the academic level of individual students as well (Kim \& Jung, 2019b). It provides students with personalized learning environments (Dawson, 2010; Park et al., 2016), instructional materials, and 
programs (Kim, 2016; Kim \& Kim, 2012, 2015) and also adjusts strategies to students' learning styles and needs (Kim, 2016; Ozaki, 2015; Zhang, 2013). Second, shadow curriculum enhances academic success and help students achieve higher school grades and test scores and eventually enter the college of their choice (Yamamoto \& Brinton, 2010). Third, the lessons in shadow curriculum are determined by each student's academic level (Kim \& Jung, 2019b). These lessons either help underachieving students catch up or help overachievers advance faster (Carr \& Wang, 2015; Entrich, 2014). This means that shadow curriculum uses remedial strategies for students who cannot follow the school lessons, and provides more advanced materials for students who are far beyond the level of other students at school (Kim, 2016; Kim \& Kim, 2012, 2015). Therefore, shadow curriculum is not only limited to remedial mainstream schooling, but it also functions for enrichment or acceleration purposes (Kim \& Jung, 2019b).

Within shadow curriculum, students and their parents have the opportunity to express their opinions about the levels of courses, various programs, instructors and instructional approaches and aggressively ask for and eventually obtain what they need due to the profit-making nature of shadow curricula (Kim \& Jung, 2019a). If shadow curriculum providers cannot or do not address these needs, students and their parents will leave and find another provider (Kim \& Jung, 2019a). "A shadow curriculum thus reflects the interests and information needs of those who have no voice in deciding what the formal curriculum should include, although they are the ones who are most influenced by it, the students" (Hagay \& Baram-Tsabari, 2010, p. 611).

\section{CHARACTERISTiCs OF A SHADOW CuRriculum}

Kim and Jung (2019b) presented six characteristics of shadow curriculum based on their definition of shadow curriculum and compared these characteristics to schooling and school curricula.

The first characteristic of shadow curriculum is that it responds to the academic and educational needs of students and parents (Bray, 2007 [1999]; Bray \& Kwo, 2013; Kim, 2016; Ozaki, 2015; Park et al., 2016). Because shadow education centers must meet consumer needs, they try to find out students wants and needs and then to respond to them (Bray, 2007 [1999]). Shadow education meets students' academic needs and help them achieve their goal (Kim, 2016) by addressing content and skills that are sometimes not covered in public schooling (Kim \& Jung, 2019b).

The second characteristics of shadow curriculum is that it strongly emphasizes students' academic achievement which is the most important reason why they take shadow education classes (Bray, 2007; Kim, 2016; Stevenson \& Baker, 1992). Research has revealed that students with either weak or strong academic performance seek shadow education (Bray 2007[1999]), and students in high ranking schools tend to use shadow education more than those in lower ranking schools (Kim 2016). It is believed that higher achievement in schools will lead students to prestigious universities and that graduates from such universities tend to be successful in their career and life (Kim \& Jung, 2019b). Thus, shadow curriculum tends to be goal specific and task oriented and helps students prepare for an exam, pass a specific test or improve a grade in a course (Aurini \& Davies, 2004; Kim, 2016; Kim \& Kim, 2012, 2015; Stevenson \& Baker, 1992; Yamamoto \& Brinton, 2010).

The third characteristic of shadow curriculum is that it focuses on school grades and test preparation (Aurini \& Davies, 2004; Kim, 2016; Kim \& Jung, 2019b; Kim \& Kim, 2012, 2015; Stevenson \& Baker, 1992; Yamamoto \& Brinton, 2010). "Shadow curriculum is oriented toward academic success, and customer satisfaction is determined by outcomes such as school grades and passing university entrance examinations" (Kim \& Jung, 2019b, p. 153). Therefore, shadow curriculum emphasizes test-taking skills to help students get higher grades on school tests and nationally standardized tests (Kim \& Jung, 2019b). In this regard, shadow curriculum providers tend to put an overemphasis on providing exam-relevant academic knowledge and test taking training, which has been criticized for causing students to believe that the only object of education is to get high scores on the tests and improve test taking skills rather than encouraging students to appreciate the significance of learning (Bray \& Kwo, 2013; Kim \& Kim, 2012, 2015; Kim \& Jung, 2019b).

The fourth characteristics of shadow curriculum is that it is "highly subject to parental investment in terms of what, where, and how students learn" (Kim \& Jung, 2019b, p. 153). Parental investment affects access to both public education and shadow curriculum; however, it functions more powerfully and relatively instantly in terms of accessing shadow education and curriculum (Kim \& Jung, 2019b). Parental investment affects the types, quality, and intensity of shadow education students receive (Kim \& Jung, 2019b) and students from wealthy families benefit from shadow education more than their less resource-rich counterparts (Byun \& Kim, 2008; Kim, 2016; Stevenson \& Baker, 1992). Empirical research argues that shadow education can deepen social and educational inequalities by providing better educational opportunities for students from economically privileged families (Dawson, 2010).

Another characteristic of shadow curriculum is personalized learning (Kim, 2016; Kim \& Kim, 2012, 2015; Mawer, 2015). Although personalized learning has been already used by public schooling and school curricula throughout the twentieth century, it is more effectually actualized and actively achieved in shadow curriculum (Kim \& Jung, 2019b). "Generally, because shadow curriculum is consumer-oriented and need-based, personalized learning is better actualized in shadow curriculum" (Kim \& Jung, 2019b, p. 155). According to Bray (2009), one-on-one tutoring is the best example of personalized learning, in that it focuses on individual students' needs, learning styles, and academic levels and goals (Kim, 2016). Unlike in public schools, where students are assigned teachers and learning materials, in Internet-based shadow education students can personalize their own learning by choosing subject areas, levels of 
courses, instructors they like, course content, learning speed, as well as where and when to study (Kim, 2016; Kim \& Jung, 2019b). However, this maximizing of student choice requires student responsibility and commitment toward learning (Kim \& Jung, 2019b).

The final characteristics of shadow curriculum is that it heightens the competitive aspect of education (Halliday, 2016; Kim \& Kim, 2012, 2015; Kim \& Jung, 2019b; Mawer, 2015). Many researchers have found that shadow curriculum has contributed to 'an overall intensification of exam competition' (Mawer, 2015. p. 133) and has turned education into a survival game (Kim \& Jung, 2019b; Holliday, 2016). This intensified competition can encourage students to view other students as rivals to defeat and to become preoccupied with test scores and school grades, rather than encouraging the intrinsic value of learning (Kim, 2016; Kim \& Jung, 2019b; Park et al., 2015; Zhang, 2013). When students consider learning only as a way of getting better scores or defeating their classmates, they risk being stuck to school grades and test scores (Kim, 2016; Kim \& Jung, 2019b; Park et al., 2015; Zhang, 2013). Thus, "markets in education raise a moral concern because of the way in which they cause, or at least exacerbate, an educational arms race that expands educational screening at the expense of educational development" (Holliday, 2016, p. 151).

\section{BACKWASH EFFECTS OF SHAdOW EdUCATION ON MAINSTREAM SchOOLING}

"Shadow education has impacted on the dynamics of teaching and learning in mainstream schools" (Yung \& Bray, 2017, p. 106). Although shadow education "may compensate for shortcomings in mainstream education, increase learning for human capital accumulation, and provide employment and incomes for tutors" (Zhang \& Bray, 2016, p. 1), it may cause distortions to the main curriculum and create additional burden on students (Dwita et al., 2018). Shadow education activities can interrupt lessons in school and produce fatigue for students and teachers (Dwita et al., 2018). "The intensive academic schedule may also deprive students of time for sports, socialization and hobbies, which are important for all-round education" (Yung \& Bray, 2017, p. 107). Scholars have reported that increased studying time and excessive involvement in shadow education have adverse effects on student development (Mori \& Baker, 2010) in that they sacrifice sleep time for studying (Gillen-O’Neel et al., 2013). Bray \& Kobakhidze (2014) argued that excessive private tutoring may have negative consequences on both students' personal development and their overall academic performance. However, students' desire to learn more or their willingness to sacrifice sleep for their future need to be considered as well (Carr \& Wang, 2015; Kim 2016).

A further dimension concerns students' attitudes towards their tutors compared with their mainstream teachers (Bray \& Kobakhidze, 2014; Yung \& Bray, 2017). "Students who pay for private lessons may respect their tutors more than their teachers who seem to come free of charge" (Bray \& Kobakhidze, 2014, p. 8). In addition, this dimension is also related to students' choice (Yung \& Bray, 2017). As students can choose their tutors but not their school teachers, they tend to appreciate their tutors more than their teachers who are imposed on them (Yung \& Bray, 2017).

Other forms of backwash may arise when teachers provide private tutoring to their own students. This means that where private tutoring is offered by teachers to students for whom they already have responsibilities at schools, teachers' malpractice and corruption are possible (Brehm, Silova, \& Tuot, 2012). In order to promote demand for supplementary lessons from their own students (Kobakhidze, 2014), teachers may intentionally only teach some part of the curriculum at school and require students to pay for learning the rest of the material in a private tutorial after school (Bray \& Lykins, 2012). They normally choose to reserve their energies and put more effort into their private classes than into the regular ones (Bray \& Lykins, 2012; Brehm et al., 2012). Moreover, some teachers may treat students who attend their tutoring classes with more attention in regular teaching, and provide them with special training and extra teaching materials (Zhang, 2013). Although in some countries, teachers are not allowed to provide tutoring to their own students (Brehm et al., 2012), "in an alternative arrangement, teachers refer their students to colleagues on a reciprocal basis rather than tutoring the students themselves" (Zhang \& Bray, 2016, p. 6).

\section{Social AND EduCATIONAL INEQUALITy CAUSED By SHAdOW EdUCATION}

While shadow education may to some extent compensate for shortcomings in public schooling, it can undermine educational reforms and deepen social inequalities (Yung \& Bray, 2017). There are two possible outcomes for investing in shadow education: first, shadow education can equalize educational opportunity by providing extra support to disadvantaged students; second, it can increase educational inequality by providing a market-based resource for advantaged students (Aurini, Davies, \& Dierkes, 2013, Entrich, 2017). Additionally, "the shadow education system of private supplementary tutoring is a serious issue with far-reaching implications for social inequalities and therefore social justice" (Bray \& Kwo, 2013, p. 480). Families, regardless of their income, invest heavily in shadow education and spend huge amounts of money (Tsiplakides, 2018). In fact, "the expansion of shadow education, some of it (especially in the mass tutorial schools) at a relatively modest price, has made private supplementary tutoring accessible not only to rich families but also to middle-class and low-income families" (Yung \& Bray, 2017, p. 105). However, since shadow education enterprises will provide services based on the tuition that families can afford, there always will be issues of educational inequality in shadow education as long as it exists (Kim et al., 2018). Therefore, students' achievement and the distribution of educational resources are heavily influenced by family background (Kim et al., 2018), and more prosperous families are able to purchase greater quantities and better qualities of supplementary 
tutoring than can less prosperous families (Bray \& Lykins, 2012; Yung \& Bray, 2017). In this regard, shadow education may lead to "the maintenance of social class in education, since students from different social classes have differential levels of access to it" (Tsiplakides, 2018, p. 75). Bukowski (2017) believed that this inequality of access to shadow education can even cause an additional gap between students of different socio-economic status.

\section{CONCLUSION}

"Student learning has been crossing the boundaries of school walls, becoming shaped and influenced by shadow curriculum" (Kim \& Jung, 2019a, p. 14) which is an individually based supplementary or enrichment curriculum provided to encourage academic success. In this transboundary culture of learning, students participate in competitive shadow education in order to achieve their best educational outcomes and school grades (Kim \& Jung, 2019a). Since shadow education is indispensable to many students, understanding shadow education is necessary for grasping the whole picture of education and more importantly student development and cannot be ignored by those who try to understand education and students' learning today (Kim \& Jung, 2019b). Therefore, curriculum research cannot be restricted to public education, but must be carried out in shadow education as well. On the other hand, shadow education has attracted increasing public concern because it exacerbates social inequalities and imposes academic burdens on students. Despite social and educational inequalities and negative backwash effects caused by shadow education, it can be concluded that shadow education and more specifically shadow curriculum, should be considered as a new research area in the field of curriculum studies in that it will expand further and will intensify due to fierce academic competition among students on achievements in standardized assessments.

\section{REFERENCES}

[1] Aurini, J., \& Davies, S. (2004). The transformation of private tutoring: Education in a franchise form. Canadian Journal of Sociology, 29(3), 419-438.

[2] Aurini, J., Davies, S., \& Dierkes, J. Eds. (2013). Out of the shadows: The global intensification of supplementary education. Bingley: Emerald.

[3] Bae, S., \& Jeon, S. B. (2013). Research on afterschool programs in Korea: Trends and outcomes. International Journal for Research on Extended Education, 1(1), 53-69.

[4] Baker, D. P., Akiba, M., LeTendre, G. K., \& Wiseman, A. W. (2001). Worldwide shadow education: Outside-school learning, institutional quality of schooling, and cross-national mathematics achievement. Educational Evaluation and Policy Analysis, 23(1), 1-17.

[5] Bray, M. \& Kobakhidze, M.N. (2014). The Global Spread of Shadow Education: Supporting or Undermining Qualities of Education? Rotterdam: Sense Publishers.

[6] Bray, M. \& Kwo, O. (2013). Behind the façade of fee-free education: shadow education and its implications for social justice. Oxford Review of Education, 39(4), 480-497.

[7] Bray, M. \& Lykins, C. (2012). Shadow education: Private supplementary tutoring and its implications for policy makers in Asia. Metro Manila, Philippines: Asian Development Bank.

[8] Bray, M. (1999). The shadow education system: private tutoring and its implications for planners. Paris: UNESCO International Institute for Educational Planning (IIEP).

[9] Bray, M. (2007 [1999]). The shadow education system: Private tutoring and its implications for planners. Paris: UNESCO International Institute for Educational Planning (IIEP).

[10] Bray, M. (2009). Confronting the shadow education system. Paris: UNESCO.

[11] Bray, M. (2011). The challenge of shadow education: Private tutoring and its implications for policy makers in the European Union. Brussels: European Commission.

[12] Bray, M. (2013). Shadow Education: Comparative Perspectives on the Expansion and Implications of Private Supplementary Tutoring. Procedia - Social and Behavioral Sciences 77, 412 - 420.

[13] Bray, M. (2014). The impact of shadow education on student academic achievement: Why the research is inconclusive and what can be done about it. Asia Pacific Educ, 15, 381-389.

[14] Bray, M. (2017). Schooling and its supplements: Changing global patterns and implications for comparative education. Comparative Education Review, 61(3), 469-491.

[15] Brehm, W., Silova, I., \& Tuot, M. (2012). The public-private education system in Cambodia: The impact and implications of complementary tutoring. Budapest: Open Society Foundations.

[16] Buchmann, C., Condron, D. J., \& Roscigno, V. J. (2010). Shadow education, American style: Test preparation, the SAT and college enrollment. Social Forces, 89, 435-462.

[17] Bukowski, P. (2017). Shadow education within the European Union from the perspective of investment in education. The European Expert Network on Economics of Education. Retrieved 07, 10, 2019, from http://www.eenee.de/eeneeHome/EENEE/Ad-Hoc-Questions.html.

[18] Byun, S. (2010). Does policy matter in shadow education spending? Revisiting the effects of the high school equalization policy in South Korea. Asia Pacific Education Review, 11, 83-96.

[19] Byun, S. Y., \& Kim, K. (2008). Parental involvement and student achievement in South Korea: Focusing on differential effects by family background. Korean Journal of Sociology of Education, 18(1), 39-66.

[20] Carr, D., \& Wang, L. C. (2015). The effect of after-school classes on private tuition, mental health and academic outcomes: Evidence from Korea. doi:10.1177/0038038516677219.

[21] Dawson, W. (2010). Private tutoring and mass schooling in East Asia: Reflections of inequality in Japan, South Korea, and Cambodia. Asia Pacific Education Review, 11(1), 14-24. 
[22] Devaney, E., Smith, C., \& Wong, K. (2012). Understanding the "how" of quality improvement: Lessons from the Rhode Island Program Quality Intervention. Afterschool Matters, 16, 1-10.

[23] Dwita, S., Cheisviyanny Ch., Helmy H., Marwan. (2018). Factors comprising Motivation to Participate in Shadow Education in West Sumatra. Advances in Economics, Business and Management Research, 57, 550-558.

[24] Entrich, S. R. (2014). German and Japanese education in the shadow-Do out-of-school lessons really contribute to class reproduction? IAFOR Journal of Education, 2(2), 17-53.

[25] Entrich, S. R. (2017). Shadow education and social inequalities in Japan: Evolving patterns and conceptual implications. Dordrecht: Springer.

[26] Evans, A., \& Leung, B. (2012). After-school programs: A potential partner to support urban youth. National Association of School Psychologists, 40(8), 1-3.

[27] Gillen-O’Neel, C., Huynh, V. W., \& Fuligni, A. J. (2013). To study or to sleep? The academic costs of extra studying at the expense of sleep. Child Development, 84(1), 133-142.

[28] Gök, F. (2010). Marketing hope: Private institutions preparing students for the university entrance examination in Turkey. In K. Amos (Ed.), International Educational Governance (pp. 123-134). London: Emerald.

[29] Hagay, G., \& Baram-Tsabari, A. (2011). A shadow curriculum: Incorporating students' interests into the formal biology curriculum. Research in Science Education, 41(5), 611-634.

[30] Halliday, D. (2016). Private education, positional goods, and the arms race problem. Politics, Philosophy \& Economics, 15 (2), $150-169$.

[31] Jung, J. -H. (2018). Decolonizing educational/curriculum studies in East Asia: problematizing shadow education in South Korea. Inter-Asia Cultural Studies, 19(2), 269-281.

[32] Kim, Y. C. (2016). Shadow education, curriculum, and culture of schooling in South Korea. New York, NY: Palgrave Macmillan.

[33] Kim, Y. C., \& Kim, P. S. (2012). Hakwon does not die; fathers die: Secrets of Korean education that Obama did not know. Paju: Academy Press.

[34] Kim, Y. C., \& Kim, P. S. (2015). The best Hakwons top 7. Paju: Academy Press.

[35] Kim, Y. Ch. \& Jung, J. -H. (2019a). Conceptualizing shadow curriculum: definition, features and the changing landscapes of learning cultures. Journal of Curriculum Studies. doi:10.1080/00220272.2019.1568583.

[36] Kim, Y. Ch. \& Jung, J. -H. (2019b). Shadow Education as Worldwide Curriculum Studies. New York: Palgrave Macmillan.

[37] Kim, Y. Ch., Gough, N., \& Jung, J. -H. (2018). Shadow education as an emerging focus in worldwide curriculum studies. Curriculum Matters. doi:10.18296/cm.0027.

[38] Kobakhidze, M. N. (2014). Corruption risks of private tutoring: Case of Georgia. Asia Pacific Journal of Education, 34 (4), 455-475.

[39] Malik, M. A. (2017). Shadow education: Evolution, flaws and further development of the term. Social Sciences and Education Research Review, 4(1), 6-29.

[40] Mawer, K. (2015). Casting new light on shadow education: Snapshots of juku variety. Contemporary Japan, 27(2), 131-148.

[41] Mori, I., \& Baker, D. (2010). The origin of universal shadow education: What the supplemental education phenomenon tells us about the postmodern institution of education. Asia Pacific Education Review, 11(1), 36-48.

[42] Nam Y. \& Chan K. (2019). The Roles of Mainstream Schooling and Shadow Education in English Language Teaching: A Case Study in Hong Kong. Education Journal. 8(1), 16-26.

[43] Ozaki, M. (2015). A juku childhood: Children's experiences in Juku attendance and its relation to their well-being in Japan (Unpublished doctoral dissertation). University of Bath, Claverton Down, UK.

[44] Paramita, S. (2015). "We follow the private tutors not the teachers": An ethnographic insight into educational practices among the students of an Indian city. International Journal of Research in Social Sciences, 4(4), 819-840.

[45] Park, H., Buchmann, C., Choi, J., \& Merry, J. J. (2016). Learning beyond the school walls: Trends and implications. Annual Review of Sociology, 42(1), 231-252.

[46] Stevenson, D. L., \& Baker, D. P. (1992). Shadow education and allocation in formal schooling: Transition to university in Japan. American Journal of Sociology, 97(6), 1639-1657.

[47] Tsiplakides, I. (2018). Shadow Education and Social Class Inequalities in Secondary Education in Greece: The Case of Teaching English as a Foreign Language. International Journal of Sociology of Education, 7(1), 71-93.

[48] Yamamoto, Y., \& Brinton, M. C. (2010). Cultural capital in East Asian educational systems: The case of Japan. Sociology of Education, 83(1), 67-83.

[49] Yang, I., \& Kim, B. C. (2010). A qualitative case study on the school life of middle school students who go to private educational institute. The Korea Educational Review, 16(3), 117-153.

[50] Yung, K. W. H., \& Bray, M. (2017). Shadow education: Features, expansion and implications. In T. K. C. Tse \& M. Lee (Eds.), Making sense of education in post-handover Hong Kong: Achievements and challenges (pp. 95-111). London: Routledge.

[51] Zhang W. \& Bray M. (2016). Shadow Education: The Rise and Implications of Private Supplementary Tutoring. (pp. 85-99). Rotterdam: Sense Publishers. doi:10.1007/978-94-6209-881-7.

[52] Zhang, Y. (2013). Does private tutoring improve students' National College entrance exam performance? A case study from Jinan, China. Economics of Education Review, 32(c), 1-28.

Yaghoob Javadi is an assistant professor of Applied Linguistics at Department of Language Teaching and Translation Studies at Islamic Azad University, Varamin-Pishva branch, Iran where he teaches post-graduate courses including Second Language Acquisition Studies, Curriculum Planning, Computer Enhanced Language Learning, and Language, Culture and Identity. His current research interests include cultural and cognitive aspects of second language acquisition, identity, CALL, curriculum planning and teacher education. 
Fakhereh Kazemirad is a $\mathrm{PhD}$ candidate in Teaching English as a Foreign Language at Islamic Azad University of VaraminPishva branch, Iran. She has been a university lecturer in Tehran, Iran since 2013, prior to which she has taught English at language institutions. 